n. ${ }^{\circ} 1$

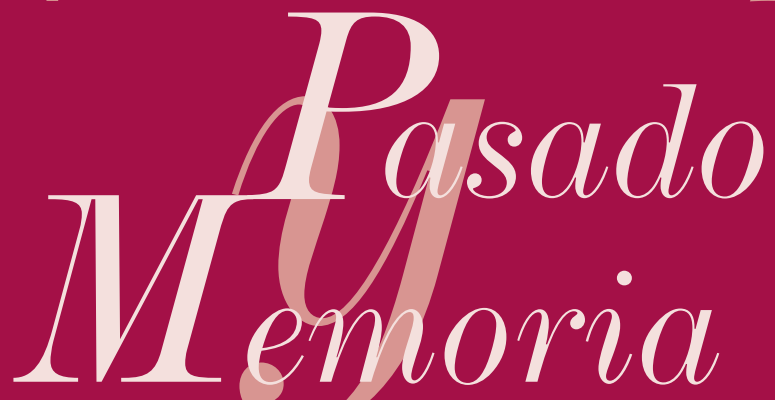

Revista de Historia Contemporánea

Instituciones y sociedad en el franquismo

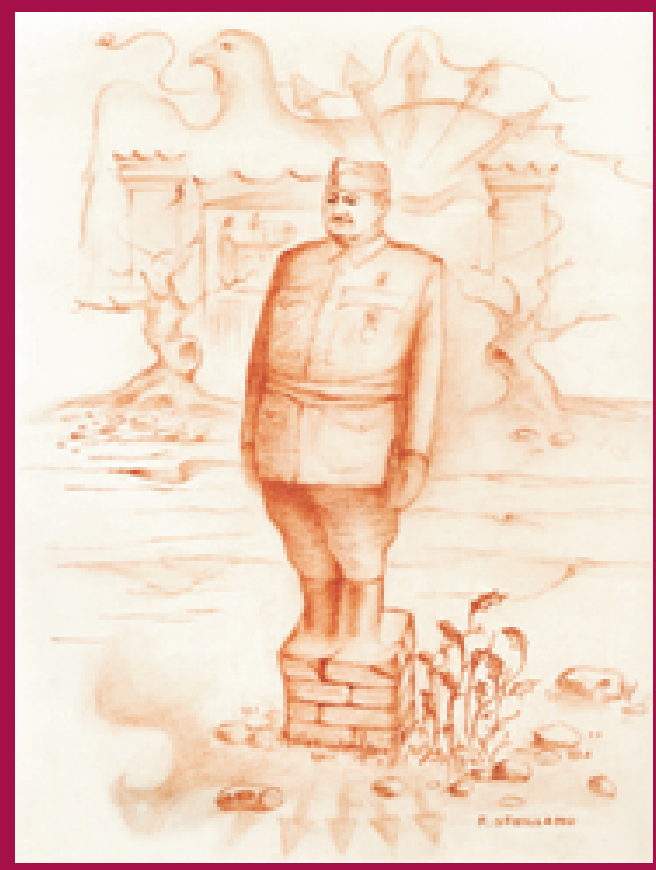




\section{Dirección: Glicerio Sánchez Recio}

Secretaría: Francisco Sevillano Calero

Consejo de redacción: Salvador Forner Muñoz, Rosa Ana Gutiérrez Lloret, Emilio La Parra López, Roque Moreno Fonseret, Mónica Moreno Seco, José Miguel Santacreu Soler, Rafael Zurita Aldeguer

Consejo asesor:
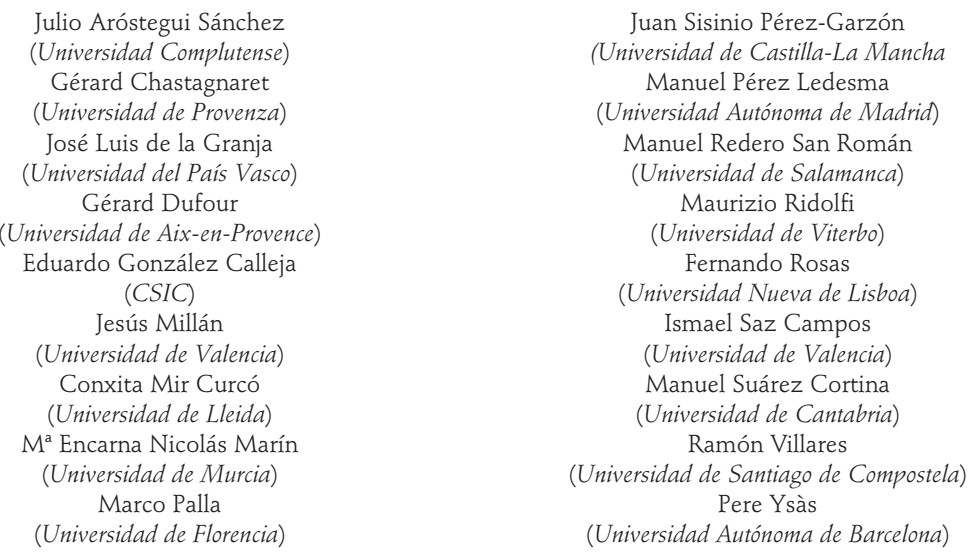

Coordinación del monográfico: Glicerio Sánchez Recio

Ilustración de la portada: El despropósito, por Francisco Sevillano Bonillo

\begin{tabular}{|c|c|c|c|}
\hline$\overline{\text { Edita: }}$ & $\begin{array}{l}\text { Departamento de Humanidades Contemporáneas } \\
\text { Área de Historia Contemporánea } \\
\text { Facultad de Filosofía y Letras } \\
\text { Universidad de Alicante } \\
\text { Apartado Postal } 99 \\
03080 \text { Alicante }\end{array}$ & Distribución: & $\begin{array}{l}\text { Publicaciones } \\
\text { Universidad de Alicante } \\
\text { Apartado Postal } 99 \\
\text { 03080 Alicante }\end{array}$ \\
\hline
\end{tabular}

Composición: Espagrafic

Impresión: INGRA Impresores

Depósito legal: A-293-2002

ISSN: 1579-3311

Reservados todos los derechos. No se permite reproducir, almacenar en sistemas de recuperación de la información ni transmitir alguna parte de esta publicación, cualquiera que sea el medio empleado -electrónico, mecánico, fotocopia, grabación, etc.-, sin el permiso previo de los titulares de los derechos de la propiedad intelectual.

\section{Estos créditos pertenecen a la edición impresa de la obra}

Edición electrónica:

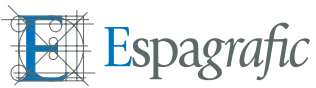




\author{
Marco Palla \\ Universidad de Florencia, Italia
}

\title{
APUNTES SOBRE EL 11 DE SEPTIEMBRE
}


Portada

Créditos

APUNTES SOBRE EL 11 DE SEPTIEMBRE $\ldots \ldots \ldots 5$

1. El acontecimiento $\ldots \ldots \ldots \ldots \ldots \ldots$

2. Las fuentes $\ldots \ldots \ldots \ldots \ldots \ldots \ldots \ldots$

3. Actualizar el pasado, historizar el presente . . . . 10

4. Las tentaciones astrológicas $\ldots \ldots \ldots \ldots \ldots 11$

5. La analogía $\ldots \ldots \ldots \ldots \ldots \ldots \ldots \ldots$

6. Datación, periodización . . . . . . . . . . 16

7. La larga duración $\ldots \ldots \ldots \ldots \ldots$

8. Maniqueísmo . . . . . . . . . . . . . 23

9. Islam, petróleo, economía mundial . . . . . . . . . 24

10. El futuro del Estado-nación $\ldots \ldots \ldots \ldots 28$

11. Zig zag $\ldots \ldots \ldots \ldots \ldots \ldots \ldots \ldots \ldots \ldots$ 


\section{Apuntes sobre el 11 de septiembre}

Marco Palla Universidad de Florencia, Italia

\section{El acontecimiento}

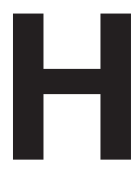
ace más de dos mil años, los historiadores griegos establecieron una primera diferencia fundamental de tipo jerárquico entre las fuentes al atribuir un valor inferior a los testimonios de segunda mano ("por haber oído") y un mayor valor probatorio a las oculares, directas, de primera mano. Si el historiador contaba con estas últimas, su autoridad en establecer hechos no podía ser objeto de escepticismo y dudas. El 11 de septiembre de 2001 es sin duda el acontecimiento de toda la historia universal que se vivió en primera persona por el mayor número de testimonios oculares. Sin embargo, resulta difícil compartir la confianza positiva de nuestros antepasados sobre la autoridad de un juicio basada en la simple testificación del hecho. 
Registrar lo que ocurrió y que millones de personas vieran directamente, aunque mediante el medio televisivo, significa ante todo definirlo, y entre el apunte del hecho y su definición se presentan unos problemas. ¿Fue terrorismo? ¿Fue un acto de guerra? ¿Fue sólo un hecho político, aunque desmesurado, o ya se ha convertido en un hecho histórico?

La historicidad/caducidad de los acontecimientos puede ser un primer y provisional punto de partida para la reflexión sobre el 11 de septiembre. A éste se une de manera inmediata la cuestión de la dramática rapidez de la evolución de los acontecimientos "todavía en curso", que se mueven siempre y de todos modos más rápido de lo que pueda hacer el observador/testigo con su voluntad de informarse y seleccionar las informaciones, racionalizar y dar sentido a lo ocurrido, conectar y comparar con su pasado, caer en la tentación de aventurar alguna previsión. También el testigo es cambiante y la contemporaneidad lo arrastra continuamente al seguimiento del discurrir de los acontecimientos, no le permite el descanso y el distanciamiento que, sin embargo, advierte como oportunos, si no necesarios. Una máxima celebre de Montaigne ha descrito esta condición psicológica y mental: "aunque el viento de la circunstancia me agita según su dirección, sin embargo más me agito y me turbo yo mismo por 


\section{Apuntes sobre el 11 de septiembre}

la inestabilidad de mi posición; y bien mirado no nos encontramos nunca dos veces en una misma situación".

Un reputado historiador americano, Arthur Schlesinger Jr., considera que dentro de 500 años todo el siglo XX se recordará sólo por el aterrizaje en la Luna de 1969. Será muy difícil que alguien esté en posición de averiguar este pronóstico arbitrario aun más que paradójico. Tomando en serio un juego así, nos podríamos preguntar si dentro de 500 años el siglo XXI será recordado también por el 11 de septiembre de 2001. No habrán respuestas a estas preguntas fútiles. Simplemente, no lo sabemos y no lo podemos saber.

\section{Las fuentes}

Un historiador puede evidentemente tener sus convicciones personales, éticas y religiosas, que no deberían hacerle sombra o incluso prevalecer en el ejercicio de su trabajo profesional. Asimismo, el historiador que se ocupa de política, que tiene experiencia y hábitos políticos, reflejados inmediatamente con el fin de formular un juicio político, tiene una supuesta ventaja en el debate público respecto al colega erudito no político. Ambos están sin embargo en la misma condición de tener que formular un juicio histórico basado en el uso escaso de las fuentes, siendo éste el nivel determinante 
para evaluar uno u otro juicio de un acontecimiento contemporáneo. La validez "profesional" de la observación de la realidad presente en su curso no puede, a su vez, competir con la reconstrucción deontológica del pasado que la historiografía cumple por estatuto.

Las fuentes disponibles son desde luego pocas y reducidas desde el punto de vista cualitativo, aunque cuantitativamente muy abundantes. Se trata en el fondo de informaciones periodísticas, de las noticias y de las imágenes de los medios de comunicación, que incluyen los comunicados oficiales y las tomas de posición públicas tanto de los terroristas como de los gobiernos de los Estados Unidos y del resto de los países que se han solidarizado con los americanos. El historiador del 11 de septiembre cuenta sólo con la cronología para enumerar este tipo de informaciones, y sobre todo no puede acceder mínimamente a la individualización y reconstrucción del proceso determinante asociado a la preparación de los atentados, a la respuesta política y militar americana y a las determinaciones que la OTAN, ONU y UE han tomado. Se constata de paso que la contribución esencial a los comentarios políticos al 11 de septiembre ha provenido en su mayor parte de los mismos periodistas, analistas políticos, expertos militares, algún economista y politólogo, pero 


\section{Apuntes sobre el 11 de septiembre}

muy raramente por historiadores, con la excepción de estudiosos especialistas en terrorismo internacional como Walter Laqueur.

Podría dar comienzo cierta exégesis sobre estas fuentes, en concreto para distinguir noticias y comentarios, o en general para plantear la cuestión de la organización de la propaganda en ambos "extraños frentes" de guerra. Conjeturar con la difusión de "falsas noticias" y dar a entender cuánto pueden influir la formación de opiniones, perjuicios, estereotipos puede ser de alguna utilidad. Otro terreno abonado para poner en práctica la capacidad histórica de los profesionales puede ser la crítica terminólogica y la puntual negación de una serie de analogías sumarias y generalmente sin fundamento que los medios de comunicación propusieron abundantemente a lo largo de las primeras semanas.

Queda la sensación de que todas estas actividades profesionales conllevan mucha dificultad y dependen a veces de la misma audacia o posiblemente del azar. El presente inmediato avanza, el historiador está desorientado por su propia y personal oscilación: ¿Qué declaración es efectivamente oficial y expresa determinaciones cargadas de consecuencias? Y ¿qué noticia es directa y totalmente veraz, y no 
por contra tendenciosa, debidamente retocada para hacer creer que las cosas son así?

\section{Actualizar el pasado, historizar el presente}

Aunque limitado, el punto de vista italiano podría aportar alguna reflexión. Grandes maestros del periodismo político y del intervencionismo de la prensa de actualidad se encuentran inmersos en una relectura/revisión general de la historia italiana (para algunos, también europea) en línea con una coherente actualización del pasado. La "legitimación” y "deslegitimación" de la historia no ha dejado libre a un solo historiador de haber hecho honestamente su propio trabajo (todos han sido legitimadores y antilegitimadores); la "muerte de la patria" ha dominado medio siglo de historia republicana; el antifascismo y la "vulgata resistenziale" han falsificado la verdad; la "enfermedad mental" de Europa (no se trata de que un médico dé este afectado diagnóstico), la que ha condicionado y paralizado casi todas las demás energías del continente, ha sido memoria deliberadamente selectiva o simple olvido. Que yo sepa, no se ha editado en Italia nada comparable a los libros del periodista/historiador Timothy Garton Ash, que se mueven con encomiable estilo sobre el terreno resbaladizo, pero potencialmente rentable, de la his- 


\section{Apuntes sobre el 11 de septiembre}

torización del presente. La instrumentalización del pasado es la ambiciosa labor de la política, cuando quiere condensar todo sobre la actualidad en sentido estricto. El historiador profesional debería hacer oír su voz alguna vez, e incluso subir también un poco el tono, para reclamar públicamente una noción "larga" y "compleja" de la contemporaneidad histórica, rechazando hacerla coincidir con (y que sea fagocitada por) la actualidad.

\section{Las tentaciones astrológicas}

La intervención política y moral, la reafirmación de principios e ideales, la protesta y la maldición a propósito del 11 de septiembre, conllevan el riesgo de impedir un intento embrionario de análisis histórico. Mejor dicho, aquellas posiciones y aquellos sentimientos expresan la urgencia política de una intervención, que pueda de alguna manera cambiar el rumbo de los acontecimientos. La intervención posible o llevada a cabo está a su vez unida con la ambición de predecir el futuro, anticiparlo, preverlo o adelantarlo. La prisa justifica el pronóstico, y el pronóstico tiene que ser formulado deprisa, si es verdad que va a explotar una tercera guerra mundial de consecuencias funestas. La urgencia de la acción está en la misma desesperación, miedo, desconcierto, sorpre- 
sa y parálisis inmediatamente percibidas. Arrojada la luz, con el estallido del acontecimiento, surgen las noticias del "compromiso", de la militancia, de la agonía comprometida, de la profecía, aunque sea en nombre de las causas más elevadas y solemnes como la no violencia y la paz perpetua. El historiador, a modo de justificación, se aleja un poco de sus archivos y sus fuentes, cierra con llave en su despacho la erudición "desinteresada" y entra en campo abierto para poner de manifiesto un estado de ánimo. ¿Por qué no se le debería consentir también a él lo que al fin y al cabo hacen todas las personas de buena voluntad?

El valor añadido de la profecía hecha por un historiador respecto a la hecha por un cualquier otro experto o principiante es, probablemente, nulo. Deslizándose inexorablemente hacia la predicción, el historiador presupone lo que debería seguir a un análisis, pospone de manera indefinida la tarea de la comprobación. Hay una diferencia sustancial, sin embargo, entre profecía/predicción y previsión histórica. Pero la previsión de los hechos sociales que estudiaba el filósofo Ludovico Limentani, o la previsión de los economistas (sobre los que ironizaba Keynes) se ejercita de todos modos en un ámbito de medio y largo plazo, extrapolando datos estadísticos y "curvas" históricas que nada tienen que ver con el pro- 


\section{Apuntes sobre el 11 de septiembre}

nóstico inmediatamente evenementielle. El historiador puede adelantar alguna previsión (Eric Hobsbawm considera este ejercicio estimulante y en alguna medida necesario), asumiendo un riesgo y peligro personal y haciendo uso exclusivamente de la experiencia profesional, no del instinto, evitando empezar a partir de una premisa dogmática ya predeterminada o ya inspirada en la mera casualidad. Entran sin embargo, en fricción, en este punto, el acontecimiento y las continuidades.

\section{La analogía}

El uso de analogías históricas, hecho muchas veces por los observadores y comentaristas periodísticos de la actualidad, y que el historiador novato se puede permitir alguna vez, se debe a menudo a un puro mecanismo de reflejo pavloviano. El historiador profesional debería evitar un uso inflacionista de las analogías e informar en consecuencia a los interlocutores. Un ejercicio motivado y prudente de comparación histórica no tiene nada que ver con este recurrir inmediato a la analogía. Pearl Harbor tiene muy poco que ver con el 11 de septiembre, pero se necesita tiempo y paciencia para poderlo explicar, y mientras tanto la analogía ha progresado y se ha introducido en un primer nivel de percepción del aconte- 
cimiento mismo por parte de la masa. Además, tal como Lewis Namier ha puesto de manifiesto, hay un doble proceso de simetría y repetición que puede llevar a la gente, e incluso a los historiadores, a "imaginar el pasado y acordarse del futuro": hay una tendencia a proyectar el propio presente hacia atrás en el tiempo reconstruyendo de esta forma una visión imaginaria del pasado, para luego proyectar el mismo presente (mejor dicho, un pasado/presente hecho de memoria, experiencia y recuerdos) en la previsión del futuro. El atentado a Francisco Fernando de Austria en Sarajevo hizo explotar la primera guerra mundial, por lo tanto el 11 de septiembre... Quien razona de esta manera olvida claramente que el atentado a Alejandro II de Rusia en 1881 no tuvo consecuencias parecidas al de Sarajevo, así como el atentado a Umberto I de Italia, Lincoln, Kennedy...

Tal vez el ojo más experto del observador directo y del testigo ocular también es falaz. El historiador Arnold Toynbee, frustrado por la ignorancia de sus compatriotas que compraban los periódicos para leer noticias sobre "The League" (la liga de fútbol), evitando leer los artículos sobre la ginebresa Sociedad de las Naciones ("The League of Nations") con ocasión de la agresión italiana a Etiopía en 1935, no encon- 


\section{Apuntes sobre el 11 de septiembre}

tró nada mejor que atribuir las causas sustanciales a la "deliberada maldad" de un único individuo, Mussolini.

Historiadores (y economistas) con experiencia directa de asuntos internacionales tuvieron en general mejor capacidad analítica respecto a otros especialistas. El hecho de formar parte de la delegación británica en la conferencia de París en 1919 fue muy beneficioso para la experiencia de comentaristas y "lectores" de la contemporaneidad como Keynes y los historiadores Toynbee, E. H. Carr y Namier. Sin embargo, no dejaron de influir orientaciones emotivas y sensibilidades políticas. El judío polaco Namier, integrante de la Agencia sionista británica, el único en protestar contra Hitler en el college oxoniense que mostraba unánime deferencia académica hacia el appeasement, echaba mano evidentemente a un excelente conocimiento de las relaciones internacionales y de la situación histórico-política de la Europa central y oriental, pero, vio el rostro demoníaco del nazismo en virtud también del instinto y a la reacción política. Fue uno de los pocos en alertar sobre el peligro en medio de la indiferencia de la gran mayoría. Por otra parte, Namier no intuyó las razones profundas del éxito nazi y acabó por codificar una precoz interpretación demoníaca de la historia alemana que hizo fortuna y cumplió cierta funcionalidad en los años siguientes al 
término de la segunda guerra mundial, pero que luego cayó en desgracia en la historiografía profesional. Carr fue vicedirector político del Times en los años de la segunda guerra mundial y escribió centenares de artículos de fondo de gran perspicacia sobre las exigencias de la paz y de la reconstrucción post-bélica, sobre objetivos político-sociales en la guerra contra el nazismo, y sobre la nueva fisionomía del gobierno mundial de la postguerra, invocando cooperación, intervención estatal, welfare y planificación. Carr prescindió de los acontecimientos militares de tal manera que no llegó a darse cuenta de un hecho ocurrido el 6 de agosto de 1945: el director del periódico, un experto periodista profesional, tuvo entonces que volver urgentemente a Londres, de un fin de semana en el campo, para que se modificara la primera plana, ya que el Times corría el riesgo de salir a la venta sin mencionar la noticia del lanzamiento de la bomba atómica.

\section{Datación, periodización}

Las definiciones políticas y jurídicas del 11 de septiembre tienden a dilatarse, prefigurando desarrollos asimismo dilatados, según se hable de "acto terrorista" o de "acto de guerra". La primera definición puede conducir a una verdadera reevaluación intencional del acontecimiento y provocar res- 


\section{Apuntes sobre el 11 de septiembre}

puestas adecuadas a tal dimensión (esto es, relativamente modestas en amplitud y duración). La segunda definición puede implicar que nos encontremos ante una verdadera y propia escalada de violencia y guerra, que conlleva aprensión y consternación (excepto para las compañías de seguros que deberían resarcir daños ingentes por acciones de terrorismo y únicamente han declarado que no aseguran a nadie, como de costumbre, por daños de guerra). ¿El historiador puede ofrecer su contribución a esta elección tan abierta, presentando posibles vías interpretativas intermedias? Una vez más, nos encontramos ante un operación profesional difícil y arriesgada, sobre todo porque -en lo referente a la segunda definición- el acontecimiento ha tenido efectivamente un verdadero séquito de reacciones posteriores. Por consiguiente, el énfasis puede desplazarse del 11 de septiembre al 7 de octubre, fecha de inicio del lanzamiento de misiles y de las incursiones aéreas anglo-americanas en Afghanistan. El punto de partida se desplaza al 7 de octubre; e incluso puede situarse en el 19 de octubre, cuando en Shanghai tuvo lugar una reunión del APEC, la organización económica de los 21 países asiáticos y del Pacífico, a lo largo de la cual se formó una especie de directorio de los Tres Grandes (Bush, Putin, Jiang Zemin), que de forma inmedia- 
ta se ha equiparado con Yalta en la enésima analogía engañosa.

El desplazamiento del énfasis del 11 de septiembre al 7 de octubre comporta el riesgo de invertir tanto la responsabilidad como sobre todo la concatenación básica y factual de desafío/respuesta de los dos acontecimientos.

Los acontecimientos consiguientes conllevan para el historiador cuestiones no sólo de simple datación de los hechos, sino de jerarquía interpretativa de los mismos, de prioridades diferentes, de opciones analíticas complejas y diferenciadas. Toda periodización necesita un punto de partida. Sin embargo, en este caso resulta claramente prematura. La datación del siglo XXI se puede seguramente establecer en el 11 de septiembre: así, además, los historiadores contribuirían a contar los años a partir de uno en vez de cero, y, además, sólo unos cuantos siglos de la historia moderna y contemporánea empezaron con un Año Primero a lo largo del cual haya ocurrido algo históricamente significativo (¿el 1501? ¿1601? ¿1701? ¿1801? ¿1901?). Para una periodización con un término a quo, y en ausencia de una referencia cierta para el fin de una época, el historiador necesita tiempo, precisa ver con más alejamiento, necesita encuadrar cierto número de décadas, no sólo el instante. Tal vez sean más 


\section{Apuntes sobre el 11 de septiembre}

útiles las referencias a las periodizaciones del "amplio Novecientos" (segunda industrialización e imperialismo a finales del siglo XIX, primera y segunda guerra mundial, gran crisis del capitalismo, descolonización, fin de la guerra fría, multipolaridad y fragmentación del mundo "global", es decir, entre lo global y lo local, en vez de insistir en el 11 de septiembre, 7 de octubre, 19 de octubre, etc... La periodización a quo del 11 de septiembre se desplaza presumiblemente (¿mucho, poco, demasiado?) hacia atrás en el tiempo, encasillada en un espacio cronológico de velocidad variable según las causas y concausas que queremos señalar. La periodización, más que la simple datación, se puede concebir también en ausencia de un término ad quem, es suficiente ser conscientes de esto y avisar a los lectores o interlocutores de este carácter necesariamente mermado. Para expresar una predilección personal sobre el análisis del 11 de septiembre, todo comentario-prólogo del historiador es más acertado que cualquier eventual y pretencioso comentario-epílogo del historiador o de quienquiera: la posición de un problema de periodización y/o interpretación puede ser, técnicamente, una de las pocas que tengan un fundamento profesional, ya que no podemos comentar el epílogo de una historia que no existe, el no-acontecimiento, un futuro que todavía no se traduce en sucesos. 


\section{La larga duración}

La liquidación en los Annales de la historia-crónica, del simple registro de los micro-acontecimientos que brotan en superficie mientras que, en lo profundo de los ritmos lentos, la historia "geográfica", económica y social se mueve con una fuerza mucho más importante, no acaba de solucionar el problema de una definición y consideración del acontecimiento-crucial, del punto de ruptura, del foco de un proceso o de una serie de procesos en curso desde hace tiempo. Sin embargo, las permanencias de las "fuerzas profundas" han permitido una reinterpretación de las fracturas y soluciones de continuidad con un extraordinario progreso generalizado de los conocimientos históricos, vigorizando la historiografía internacional y permitiendo el examen de un siempre mayor número de paradigmas interpretativos. La toma de la Bastilla el 14 de julio, octubre de 1917 y los "diez días que cambiaron el mundo", el "viernes negro" del octubre neoyorkino de 1929, Dantzig, Pearl Harbor, la caída del Muro de Berlín en otro fatídico 89, son hoy en día generalmente encasillados en un contexto, más que analizados como hechos particulares por el historiador, para quien sería inconcebible definirlos como eventos, dado el nivel de descrédito del término entre los expertos. No resulta curioso o anecdótico evocar las cir- 


\section{Apuntes sobre el 11 de septiembre}

cunstancias en las que se elaboró el perfeccionamiento historiográfico de la noción de larga duración. Habiendo sido hecho prisionero como por los alemanes tras la caída francesa en junio de 1940, Fernand Braudel impartió algunos cursos "carcelarios" para sus compatriotas también prisioneros en Alemania. Procuró mantener alta la moral de sus compañeros, decepcionados y desanimados por las continuas victorias militares del Tercer Reich en los años 1940-42. Ante cada nuevo éxito alemán, Braudel mostraba su escepticismo sobre el significado de aquella batalla concreta, aquel determinado hundimiento del frente, comentando: "son sólo acontecimientos".

Orlando Figes, en La tragedia di un pueblo incluye la historia de la revolución rusa en 1891-1924 y considera, ciertamente con muchos elementos de provocación, octubre de 1917 como un acontecimiento casi secundario, resumiéndolo esencialmente en la expoliación de las colecciones preciadas de vinos y licores de las bodegas del Palacio de Invierno por parte de los insurrectos.

Si el 11 de septiembre es el momento "tras el cual ya nada será igual que antes", el historiador tiene el deber de avisar que este dicho se ha repetido hasta el aburrimiento para casi todo género de acontecimientos del pasado. Desde este 
punto de vista, parecen ya olvidadas las definiciones de la muy reciente guerra de Kosovo de 1999 como "fin de siglo", cierre de una era tras la que nada permanecía como antes: los numerosos análisis sobre aquella guerra que fueron elaborados a lo largo de su desarrollo, incluso antes de que terminara, son hoy en día una clara prueba de su inadecuación y caducidad, como es natural.

La "valencia" metodológica y epistemológica del criterio de la larga duración consolida, por un lado, el concepto de una historia contemporánea "no breve", no circunscrita sólo a las últimas décadas; sin embargo, por otro lado, puede hacer reflexionar sobre la inadecuación de fijar el comienzo de la historia contemporánea en la "doble revolución". La revolución industrial inglesa de la mitad del siglo XVIII fue precedida en Inglaterra, en Alemania, en Francia, esto es, en Europa, por una lenta y no lineal fase histórica proto-industrial, y si tenemos en cuenta ésta, la fractura de los años 1750-80 resulta "menos revolucionaria". Por otro lado, la industrialización efectiva de una parte de Europa y del mundo extra-europeo es un fenómeno más del siglo XX que del siglo XIX. La "ruptura" de 1789 puede parecer significativa para la historia europea contemporánea, pero demasiado remota para la historia mundial al comienzo del siglo XXI. Sin dar excesiva im- 


\section{Apuntes sobre el 11 de septiembre}

portancia a las convenciones académicas, hoy en día la historia moderna y la historia contemporánea "comprenden" aproximadamente dos siglos y medio cada una, y esta "equiparación" necesita tal vez especificaciones, actualizaciones, mayores integraciones recíprocas. El mundo contemporáneo contiene demasiados elementos no-modernos para ser estudiado sólo con la herramienta conceptual del siglo XX; sin embargo, el "amplio" siglo XX (desde 1870 hasta 2001) se ha hecho bastante complicado, necesitando esta periodización un esfuerzo particularmente intenso, concentrado y unitario de investigación y análisis.

\section{Maniqueísmo}

No hay sólo un frecuente uso del maniqueísmo en la opuesta propaganda de Bin Laden y Bush, o en el replantamiento de una visión del mundo sustancialmente teológica, dominada por el binomio Bien-Mal. Ni hay sólo un maniqueísmo antiislámico y un maniqueísmo antiamericano. Existen, en el terreno más específicamente "científico", opciones extremadamente divergentes, que pueden introducir elementos de maniqueísmo en la práctica historiográfica y en el debate crítico. La interpretación dual del curso actual de la historia mundial oscila peligrosamente entre "el fin de la Historia" (el Bien, 
el triunfo o victoria de Occidente, del Libre Mercado, de los Valores Humanos Democráticos) y la catástrofe próxima de la "disputa entre civilizaciones" destinada a suprimir para siempre la paz y a sustituir las "antiguas" guerras por divisiones mucho más profundas y duraderas de los pueblos y de las culturas recíprocamente y permanentemente en conflicto. Tal vez, la corporación de los historiadores ha analizado estas teorías de manera demasiado distraída, y sobre todo no se ha esforzado en contraponer una propuesta positiva de "lectura" del mundo, que por lo menos evitara el frecuente recurrir a explicaciones "de última hora", monocausales y monofactoriales. Evocar la complejidad y las hipótesis multifactoriales no significa abandonar la necesidad de una explicación, sino establecer las precondiciones para tratar de formularla in itínere, sabiendo que se podrá mejorar e integrar cuantas más pruebas "experimentales" estén disponibles para apoyarla (o dejarla caer).

\section{Islam, petróleo, economía mundial}

Por citar una vez más a Braudel, hace décadas el historiador de Las civilizaciones actuales (obra notable, aunque probablemente no la mejor) conseguía sorprender a algún lector suyo desprevenido, porque muy a menudo, en vez de tratar 


\section{Apuntes sobre el 11 de septiembre}

de la década de 1960, años en los que preparaba su libro, hablaba del año Mil, de Mahoma, Carlomagno y de Lepanto. O incluso en lugar de describir el cuadro político de las repúblicas islámicas pertenecientes a la URSS, o las consecuencias sobre aquéllas de la revolución de octubre, escrutaba la persistencia en ellas de cuadros mentales y estructuras de civilizaciones milenarias. Un primera aproximación plurisecular a los problemas del mundo actual: si hubiera enfocado su estudio sobre la actualidad de sus años 60, el libro de Braudel habría captado mayor interés entonces, pero muy pronto se habría quedado obsoleto. Al contrario, hoy en día conserva su peso y gran utilidad. Releer las páginas de aquel libro sobre el Islam, junto a muchos otros textos actualizados, puede representar el referente bibliográfico para expresar una opinión meditada sobre este tema, sin tener que ser en todo caso "especialistas".

Asimismo, la cuestión del petróleo debe ser enfocada de manera articulada sin dar la impresión, en quien la evoca limitándose a mencionarla, que constituye solo una especie de residuo de economicismo determinista. El multimillonario árabe Bin Laden tiene sin duda objetivos de poder y busca para influir tal vez en la lucha interfamiliar de sucesión abierta entre ramas rivales de la monarquía saudí. $Y$ dado que 
Arabia Saudí controla el 25 por ciento de la producción mundial de petróleo, no resulta ciertamente indiferente la orientación política de su dirigente. El presidente Bush, elegido con el apoyo determinante del lobby petrolífero texano, tiene seguramente una notable sensibilidad por el tema. Es justo, pues, señalar este aspecto de la cuestión, esta implicación, como uno de los aspectos más trascendentales en el caso de complicaciones catastróficas del conflicto en curso: estos aspectos podrían representar el elemento desencadenante de un conflicto mundial por el poder, en donde el control de los recursos energéticos sería un elemento central. También para delinear estos escenarios hacen falta competencias, tiempos razonables, pero ciertamente no breves de elaboración, y resistencia ante la impaciencia de escribir el epílogo antes del prólogo.

Sobre la hipótesis, ni abstracta ni peregrina, de una profundización del estancamiento económico actual en verdadera y duradera recesión mundial, el historiador puede confirmar ante todo que el 11 de septiembre podría funcionar sólo como acelerador de tendencias ya en marcha. La segunda economía del planeta, la japonesa, está en una fase de estancamiento desde hace una década y no muestra ninguna señal de recuperación. Alemania, Italia y otros países de la 


\section{Apuntes sobre el 11 de septiembre}

UE están aminorando la velocidad de crecimiento respecto a los niveles tampoco "milagrosos" del fin de los años 90. El 2000 ha sido un buen año para las principales economías internacionales (esto es, de los países avanzados), pero la burbuja financiera de la nueva economía americana y europea ya había explotado en marzo de 2000, anticipando los desarrollos actuales y las incertidumbres que, hoy en día, se refieren más a la intensidad y duración de una crisis económica que a la casi certeza de que ésta aparecerá. El Banco Mundial considera que una recesión mundial comportaría una disminución del 20 al 40 por ciento de las exportaciones asiáticas, afectando de manera especial a la China recién admitida a la OMC; el descenso estimado del 1 por ciento del PIB mundial tendría consecuencias graves sobre todo para los países más pobres, además de 40.000 muertos de hambre (junto a los "habituales") entre los niños de edad inferior a los 5 años concentrados en el África subsahariana. El multimillonario-terrorista que dirige Al Qaeda desde luego no derrama lágrimas por el hambre en el mundo.

El tema puede derivar hacia la globalización "inicua", la injusta distribución de la innovación tecnológica, el reiterado desequilibrio entre norte y sur, el boom demográfico y las grandes migraciones, el deterioro ambiental, elementos to- 
dos que confirman el dato histórico de la crisis del Estadonación.

\section{El futuro del Estado-nación}

Las "grandes fuerzas del cambio", según Paul Kennedy, son todas de carácter transnacional, determinan un "desafío" mundial, no pueden ser analizadas ni con la percepción y lógica de las políticas nacionales, ni con las herramientas prácticas de iniciativa y de "respuesta" del Estado-nación. El 11 de septiembre confirma en parte esta tendencia histórica reciente; sin embargo podría también desmentirla en aspectos nada secundarios. La vulnerabilidad americana aparece como un potencial tema "histórico" bastante sorprendente. Ésta podría relanzar el miedo y la necesidad de seguridad en niveles tan diseminados y amplios como para poner en duda cualquier paradigma ideológico sobre "más privado, menos Estado". Asistencia y seguridad social, transportes, protección y seguridad diaria, e incluso políticas de seguros y de prevención, que se concretaron con la doble "revolución conservadora" thatcheriano-reaganiana de hace veinte años, podrían sufrir un cambio clamoroso de prioridades en las políticas públicas. Todavía es pronto para certificar el declive de la teología liberal y privatizadora, o para asistir al retorno ge- 


\section{Apuntes sobre el 11 de septiembre}

neralizado del deficit spending o de la intervención pública en la economía. Sin embargo, se están poniendo las bases para un cambio mental de masa, tal vez dirigido a invocar "más público, más Estado" por razones eminentemente prácticas y no tanto por la bondad teórica de los ingredientes ideológicos en cuestión.

Quizás el declive del Estado-nación puede ser mejor analizado por los historiadores como declive de determinados estados y determinadas potencias. El "ascenso y declive" de grandes imperios, de países-guías, de potencias hegemónicas, representa un tema de amplio debate historiográfico, diferenciando el análisis y llegando a una generalización sólo después de un examen metódico de casos concretos y contextos específicos. La crisis del Estado-nación (su muerte es más aparente que real) no se puede, como ejercicio de previsión histórica, datar en un año preestablecido o en un período convencionalmente circunscrito. Es un proceso típico de largo recorrido temporal, con una larga incubación y susceptible de prosecución no lineal.

\section{Zig zag}

Hans Magnus Enzensberger (Zigzag, Barcelona, Anagrama, 1999) escribe: "la torpeza con la que los gobiernos han re- 
accionado ante los recientes cambios ocurridos en Europa, su carente determinación, no es un acontecimiento engorroso y casual que se puede solucionar con una simple sustitución de personas; al contrario, se debe a la verdadera imposibilidad de poder predecir los procesos sociales, de clasificarlos de manera general y controlarlos por lo tanto desde arriba. Esto no vale sólo para los casos más extremos. Estos últimos, de hecho, demuestran solamente que el camino vacilante e inestable de los acontecimientos no es nada más que la cosa más normal y por consiguiente más imprevisible del mundo"; "el muy discutido post-moderno [...] no ha sido capaz de comprender la dinámica profunda propia de la nocontemporaneidad. Ya la fórmula con la que ha entrado en la escena muestra su gran nivel de vinculación al pensamiento secuencial: o sea, a aquel esquema según el que una época -o un episodio- sigue a otra y la sustituye, para luego, como en una cadena de montaje, dar lugar lo más pronto posible a la siguiente. Es en este concepto extraordinariamente simple donde sobrevive el dogma central de la modernidad, un dogma que ha conseguido superar todos los desajustes y las dudas interiores del siglo"; "la más banal de las concepciones del tiempo [...] encasilla todo lo que ha ocurrido o ocurrirá a lo largo de una línea recta y considera el presente como un punto errante que separa netamente el pasado del 


\section{Apuntes sobre el 11 de septiembre}

futuro. Es una teoría de una sencillez casi envidiable que da lugar directamente a una tautología del tipo: lo que ha sido, ha sido. Quien comparta semejante concepción, pues, tendrá que rendirse ante todo a la cuestión de la posibilidad del recuerdo; y con mayor razón se dará cuenta de la no-contemporaneidad del presente", esto es "el anacronismo"; "si junto a la concepción lineal del tiempo [...] conseguimos imaginar una estructura del tiempo histórico complementario, será tal vez más fácil comprender los desperdicios de la historia. [...]. El encuentro entre diferentes estratificaciones históricas no ocasiona pues el retorno del igual, sino una interacción recíproca de la que, puntualmente y de ambas partes, emerge algo nuevo. En este sentido, pues, no es imprevisible sólo el futuro. También el pasado está sometido a un continuo cambio. Ante los ojos de un observador que no dispone de una visión conjunta de todo el sistema, éste se transforma incesantemente".

(traducción del italiano de Gaetano Cerchielo, revisada por Francisco Sevillano Calero) 